\title{
A ESTÉTICA DOS EXTREMOS: NOTAS SOBRE A RELAÇÃO ENTRE A ARTE RUPESTRE E A REPRODUTIBILIDADE TÉCNICA EM THEODOR ADORNO
}

\author{
Jéverton Soares dos Santos ${ }^{1}$ \\ Robson da Rosa Almeida ${ }^{2}$ \\ Pontifícia Universidade Católica do Rio Grande do Sul (PUCRS)
}

\begin{abstract}
RESUMO:
O artigo propõe uma aproximação entre dois campos de pesquisa distintos, mas com notórias afinidades eletivas: o campo da arqueologia e o da estética filosófica. Pretende-se saber de que modo, no interior do pensamento dialético de Adorno, articulam-se os conceitos de pré-história e proto-história, tendo como fio condutor a temática da arte rupestre e a sua contrapartida moderna, isto é, a reprodutibilidade técnica. Tal aproximação tem como ponto de partida um instigante parágrafo da obra póstuma de Adorno, "Ästhetische Theorie", presente na subseção assim classificada por Rolf Tiedmann como "Moderne Kunst und Industrielle Produktion", no qual Adorno afirma que há uma convergência entre a arte rupestre e a câmera fotográfica, que se daria na objetivação (Objektivation), isto é, na ação de separar o ato subjetivo do objeto que é visto. A partir desta constatação, a contribuição maior deste artigo estaria em identificar uma espécie de protohistória da reprodutibilidade técnica no mundo pré-histórico. Deste modo, numa perspectiva radicalmente dialética pode-se dizer que o progresso virtual e tecnológico sentido nas últimas décadas não representa algo qualitativamente novo na história humana, sendo apenas um desdobramento de uma tendência já contida na pré-história, algo que nos leva a crer que não conseguimos ainda superar o estado de imanência mítica denunciado amplamente por Adorno e Horkheimer na "Dialektik der Aufklärung. Para demonstrar isto o presente artigo almeja reconstruir as principais linhas de força da "Dialética do Esclarecimento", centrando na categoria de mito (Seção 1). Após, pretende apresentar a relação entre pré-história e protohistória no contexto do pensamento adorniano, especialmente nas obras e

\footnotetext{
${ }^{1}$ Doutorando em filosofia pela Pontifícia Universidade Católica do Rio Grande do Sul (PUCRS), Rio Grande do Sul - Brasil, sob orientação do Prof. Dr. Nythamar de Oliveira. Bolsista CAPES. E-mail: jevertonsoares@ hotmail.com .

2 Doutorando em filosofia pela Pontifícia Universidade Católica do Rio Grande do Sul (PUCRS), Rio Grande do Sul - Brasil, sob orientação do Prof. Dr. Ricardo Timm de Souza. Bolsista CAPES. E-mail: robsonrosaalmeida@yahoo.com.br .
} 
nos ensaios do período intermediário de sua bibliografia, tais como "Minima Moralia" e "Prismen" (Seção 2). Por último, deseja apresentar algumas reflexões de Adorno sobre a arte rupestre e a reprodutibilidade técnica presentes na Teoria Estética (Seção 3).

PALAVRAS-CHAVE: Reprodutibilidade Técnica; Arte Rupestre; Imanência Mítica.

\title{
THE AESTHETICS OF EXTREMES: NOTES ON THE RELATIONSHIP BETWEEN ROCK ART AND TECHNICAL REPRODUCIBILITY IN THEODOR ADORNO
}

\begin{abstract}
:
The article proposes a connection between two different fields of research, but with notorious elective affinities: the field of archeology and the philosophical aesthetics. It is intended to find, within the dialectic of Adorno, how articulate the concepts of prehistory and proto-history, it having as a guide the theme of rock art and its modern counterpart, the reproducibility technique. Such an approach takes as its starting point an intriguing paragraph of posthumous Adorno's work, "Ästhetische Theorie," this subsection thus classified by Rolf Tiedmann as "Moderne Kunst und Industrielle Produktion" in which Adorno asserts that there is a convergence between the rock art and photographic camera, that occurred in objectification (Objektivation), e.g., in the action to separate the subjective act of the object that is seen . From this finding the greatest contribution of this paper was to identify a kind of mechanical reproduction proto-history in the prehistoric world. Thus, in a radically dialectical perspective it can be said that the virtual progress and technological sense in recent decades does not represent something qualitatively new in human history, being only an offshoot of a trend already contained in prehistory, which leads us to believe we have not yet overcome the state of mythical immanence widely denounced by Adorno and Horkheimer's "Dialectic of Enlightment. To demonstrate that this article aims to reconstruct the main thrust of the "Dialectic of Enlightenment", focusing on the myth category (Section 1). After it intends to present the relationship between prehistory and protohistory in the context of Adorno's thought, especially in the construction and essays of intermediate period of his thought, such as "Minima Moralia" and "Prismen" (Section 2). Finally, it wants to present some Adorno's reflections on rock art and mechanical reproduction present in Aesthetic Theory (Section 3).
\end{abstract}

KEYWORDS: Technical reproducibility; Rock art; Mythical immanence.

A estética dos extremos: notas sobre a relação entre a arte rupestre e a reprodutibilidade técnica em Theodor Adorno - Jéverton Soares dos Santos; Robson da Rosa Almeida 


\section{O problema da Imanência Mítica na Dialética do esclarecimento}

Não seria nenhum exagero de nossa parte começar este trabalho afirmando que a obra "Über den Begriff der Geschichte" (Sobre o Conceito de História) de Walter Benjamin, em seu conjunto, explicita avant la lettre o cerne da crítica da Dialética do Esclarecimento ${ }^{3}$, escrita a quatro mãos por Adorno e Horkheimer na década de 40, qual seja a de que toda a civilização até hoje era feita de "luzes aprisionadas na imanência mítica, que, por si mesma, sufocavam no nascimento qualquer possibilidade de fugir da imanência mítica"( WIGGERSHAUS, 2002, p. 358). Isso quer dizer que a humanidade tem diante de si a difícil tarefa de superar a situação de préhistória natural - de selvageria, apesar de todo o progresso científico e tecnológico - em que tem estado submetida, sob o risco de sua própria autodestruição.

Deste modo, a própria ideia de "Kontinuum der Geschichte" (continnum da história), tão cara para compreensão de "Über den Begriff der Geschichte", pode ser interpretada como sinônimo de "Immergleiche" (sempre-igual), o princípio da imanência mítica, cuja quinta-essência é proclamada no Livro bíblico do Eclesiastes (1: 9), no qual se lê: "O que foi, será, o que se fez, se tornará a fazer: nada há de novo debaixo do sol" ${ }^{4}$. Tal ideia é duramente criticada na passagem a seguir, retirada da primeira parte da Dialética do Esclarecimento:

O princípio da imanência, a explicação de todo acontecimento como repetição, que o esclarecimento defende contra a imaginação mítica, é o princípio do próprio mito. A insossa sabedoria para a qual não há nada de novo sob o sol [...] reproduz tão-somente a sabedoria fantástica que ela rejeita: a ratificação do destino que, pela retribuição, reproduz sem cessar o que já era. O que seria diferente é igualado ${ }^{5}$.

O continuum significa, dentre outras coisas, a persistência do mito. Mito aqui não significa um tipo supersticioso e antiquado de visão de mundo. Significa antes um modus operandi do pensamento e da história, que a contragosto de sua aparente superação histórica através da razão instrumental moderna, permanece como essência da economia capitalista ${ }^{6} \mathrm{e}$

\footnotetext{
${ }^{3}$ De acordo com Susan Buck-Morss, "Dialektik der Aufkläurung foi a tentativa de levar a cabo precisamente a tarefa cognitiva que Benjamin havia identificado em 1940, como a mais urgente, isto é, desmantelar o mito na história como progresso" (BUCK-MORSS, 1981, p.134).

${ }^{4}$ Bíblia de Jerusalém. Porto Alegre: Paulus, 2002, p. 657.

5 ADORNO, T; HORKHEIMER, M. Dialética do esclarecimento: fragmentos filosóficos. Rio de Janeiro: Jorge Zahar Editor, 1985. Reimpressão de 2006. p. 23.

6 “Os dois náufragos prototípicos fazem de sua fraqueza - a fraqueza do indivíduo que se separa da coletividade - sua força social. Entregues ao acaso das ondas, desamparadamente isolados, seu isolamento dita-lhes a perseguição implacável do interesse atomístico. Eles
} 
da ciência hodierna (ADORNO, 2009, p.19). A essência deste modus operandis é nada mais que o princípio da equivalência ou aquilo que Adorno chamou na Dialética Negativa de "compulsão à identidade" (ADORNO, 2009, p.19). Por essa razão os mitos, segundo os autores de Dialética do Esclarecimento, já eram esclarecimento:

\begin{abstract}
Mas os mitos que caem vítimas do esclarecimento já eram o produto do próprio esclarecimento. No cálculo científico dos acontecimentos anula-se a conta que outrora o pensamento dera, nos mitos, dos acontecimentos. O mito queria relatar, denominar, dizer a origem, mas também expor, fixar, explicar (ADORNO; HORKHEIMER, 2006, p.20).
\end{abstract}

Este processo mítico de padronização da diferença e do particular sob a égide do padrão de identidade e da universalidade perpassa toda Dialética do Esclarecimento, sendo que os próprios autores tentam oferecer um modelo de dialética alternativo a este processo. A dialética oferecida por Adorno e Horkheimer visa dar prosseguimento de modo crítico ao processo de autointerpretação filosófica da modernidade propiciada sui generis por Hegel e Nietzsche. Adorno e Horkheimer buscam demostrar que os germens do Iluminismo já se encontram tácitos em uma época bastante remota: a Grécia antiga. Em termos bem gerais, o objetivo principal da obra é mostrar que a cada vitória que a civilização deu sobre a natureza externa foi paga com a regressão da natureza interior. Nesse ínterim, os autores mostram que o princípio da organização social - pedra pilar de qualquer ideia de civilização - foi ardilosamente solapado pelo princípio da autopreservação. Por uma espécie vingança da natureza oprimida a selvageria inerente a ela acaba invadindo as esferas que deveriam servir de alternativa à brutalidade do mundo natural: a cultura e a política. Tal processo provoca uma turva fusão entre poder e vida. O homem passa exercer domínio sobre os outros homens. E aquilo que poderia se esperar de uma sociedade "racionalizada" - a emancipação do mito - se mostra irreal: a mitologia invade a esfera profana constituindo um retorno do esclarecimento a sua origem mítica.

Mesmo sem ser o único referencial teórico do livro, o ponto de partida dos autores é o livro "Novum Organun", de Francis Bacon, publicado em 1620, no qual é defendido o imperativo de conceber o saber em termos de poder. A tese baconiana, citada pelos autores da Dialética do Esclarecimento, de que "hoje, apenas presumimos dominar a natureza, mas, de fato, estamos submetidos à sua necessidade; se, contudo nos deixássemos guiar por ela na invenção, nós a comandaríamos na prática"

personificam o princípio da economia capitalista, antes mesmo que esta recorra aos serviços de um trabalhador: mas os bens que salvam do naufrágio para empregar em um novo empreendimento transfiguram a verdade segundo a qual o empresário jamais enfrentou a competição unicamente com o labor de suas mãos" (ADORNO; HORKHEIMER, 2006, p. 58-9). 
(ADORNO; HORKHEIMER, 2006, p.17), constitui o verdadeiro elo entre a mentalidade pragmática moderna e a lógica mítica da pré-história, pois vincula como dever da ciência aquilo que já residia tacitamente na mitologia, isto é, o domínio estratégico sobre a natureza: "Os mitos, como os encontram os poetas trágicos, já se encontram sob o signo daquela disciplina e poder que Bacon enaltece como o objetivo a se alcançar" (ADORNO; HORKHEIMER, 2006, p.20).

O caráter de continuidade mitológico deixa-se transparecer também pela naturalização da selvageria no interior da chamada indústria cultural, que é a cultura de massa do capitalismo tardio, a qual reproduz, de modo descontraído, a mítica "violência nua e crua" (ADORNO; HORKHEIMER, p.49):

\begin{abstract}
Assim como o Pato Donald nos cartoons, assim também os desgraçados na vida real recebem a sua sova para que os espectadores possam se acostumar com a que eles próprios recebem. O prazer com a violência infligida ao personagem transforma-se em violência contra o espectador, a diversão em esforço (ADORNO;HORKHEIMER, 2006, p.114).
\end{abstract}

Além disso, pode-se mencionar outra característica comum entre mito e esclarecimento, a saber, a necessidade de explicar os fenômenos da natureza, algo que se torna prelúdio para a ciência moderna: "O mito queria relatar, denominar, dizer a origem, mas também expor, fixar, explicar" (ADORNO, HORKHEIMER, 2006, p.20). Isso não significa, no entanto, que o mito e a ciência sejam equivalentes. A falar da verdade, há de se compreender que a narrativa mítica foi um passo decisivo para a constituição da ciência moderna, o que não quer dizer que a pretensão de verdade comece apenas no mito. Pode-se dizer que com a magia já há esta tentativa de dominar a natureza, ainda nela haja uma relação mais mimética com o objeto. Se, de um lado, a magia, principal manifestação da consciência primitiva, funciona por meio daquilo que os autores da Dialética ${ }^{7}$ chamam de "substitutividade específica", ou seja, a crença de que o que acontecia com um objeto que representasse o alvo da feitiçaria (a lança deste, seu fio de cabelo ou um pedaço de sua vestimenta) afetava ao mesmo tempo a pessoa em carne e osso, por outro lado, a ciência, principal instrumento da consciência moderna, opera por meio de um necessário distanciamento entre sujeito e objeto, que expande o princípio mítico da substitutividade específica, tornando-o universal: "A substitutividade converte-se em fungibilidade universal. [...] Como a ciência, a magia visa fins, mas ela os persegue pela mimese, não pelo distanciamento progressivo em relação ao objeto" (ADORNO; HORKHEIMER, 2006, p.22).

\footnotetext{
${ }^{7}$ Doravante usaremos a palavra Dialética, em caixa alta e itálico, para designar a obra conjunta de Adorno e Horkheimer.
} 
Isto quer dizer que a Aufklärung é mais do que simplesmente a "saída do homem de sua menoridade, pela qual ele próprio é responsável" como pensava Immanuel Kant. Na verdade, os autores elevam a definição kantiana de esclarecimento até o ponto de reductio ad absurdum: não é o "sapere aude" ou a coragem de se guiar pelo próprio entendimento que constitui a motivação principal do esclarecimento, mas o oposto disso, qual seja o medo (Furcht) do homem diante da natureza, manifesto pela compulsão humana por exercer domínio sobre ela, mediante o conhecimento de suas determinações objetivas e subjetivas: "Do medo o homem presume estar livre quando não há nada mais de desconhecido" (D.E. p.26). Também em outra passagem os autores afirmam que: "O sistema visado pelo esclarecimento é a forma de conhecimento que lida melhor com os fatos e mais eficazmente apoia o sujeito na dominação da natureza" (Idem, p.72). Mais importante ainda é compreender a chamada entronização "entre meio como fim" como um elemento fundamental do capitalismo tardio, mas que já era perceptível na "Odisseia” de Homero:

\begin{abstract}
No instante em que o homem elide a consciência de si mesmo como natureza, todos os fins para os quais ele se mantém vivo o progresso social, o aumento de suas forças materiais e espirituais, até mesmo a própria consciência - tornam-se nulos, e a entronização do meio como fim, que assume no capitalismo tardio o carácter de um manifesto desvario, já é perceptível na proto-história da subjetividade (ADORNO; HORKHEIMER, 2013, p.53).
\end{abstract}

De acordo com esta análise (Cf. DUARTE, 1997), a negação da natureza no homem - cerne da racionalidade civilizatória - conduz paradoxalmente à proliferação da irracionalidade mítica. Na mentalidade mítica, o homem não se via separado do meio natural que o rodeava. Por esse motivo, na pré-história não havia qualquer indício de um sujeito propriamente dito. Com o avanço em direção à civilização, o homem passou a não se reconhecer como ser integrante da natureza, negando-a. A própria constituição do eu está associada com esse distanciamento progressivo com o mundo físico. Mas tal desligamento com o mundo exterior gera uma ambiguidade na consciência primitiva. Se, por um lado, o indivíduo primitivo se sente aliviado por se livrar do jugo da natureza, por outro lado ele percebe que tal desligamento simboliza algo de profundamente desconhecido e indeterminado, algo que gera angústia (Angst) nele, a qual constitui uma forma de medo que o homem acredita conseguir se libertar através do conhecimento enquanto poder. Como indivíduo o homem percebe que precisa lutar sozinho para garantir sua subsistência, mas isso é angustiante para ele. Desse modo, a própria ideia de sujeito nasce com a consciência da necessidade de garantir sua própria sobrevivência no plano material. Quando ele conseguiu isso começou a desenvolver a racionalidade como ferramenta para lhe garantir tanto a manutenção de meios imediatos 
de subsistência quanto uma forma de organização social que permitisse a extensão dessa possibilidade de subsistência. Porém, o problema é que nesse ínterim, o primeiro objetivo, que é também o mais básico e imediato, passou a solapar o segundo, gerando àquela "entronização do meio como fim": "Com a negação da natureza no homem, não apenas o telos da dominação externa da natureza, mas também o telos da própria vida se torna confuso e opaco" (ADORNO; HORKHEIMER, 2013, p.53). Isso significa que não é mais o princípio da organização social que importa e sim a necessidade primitiva de garantir a sobrevivência a qualquer preço, gerando um estado no qual Rodrigo Duarte intitula como "ditadura da autoconservação" (DUARTE, 1997, p.52), que se manifesta, dentre outras formas, no fato de que o sujeito desde cedo é levado a reconhecer o poder como princípio de todas as relações na sociedade capitalista. Por isso que, para Adorno e Horkheimer, o esclarecimento é a radicalização da angústia mítica (ADORNO; HORKHEIMER, 2013, p.26), já que nele ocorre a fusão entre poder e saber tão almejada pela consciência mítica.

Por isso que, ao longo da marcha civilizatória, o comportamento mimético, ou a "adaptação orgânica ao outro" (ADORNO, HORKHEIMER, 2013, p.149), isto é, a forma de conduta pela qual o indivíduo se torna semelhante ao mundo exterior sem perda subjetiva, foi sendo gradativamente substituída pela "falsa projeção", que é o reverso da mímesis, ou seja, uma forma de comportamento na qual indivíduo torna o mundo exterior semelhante ao interior (ADORNO, HORKHEIMER, 2013, p.154). Essa inversão diabólica está na base da própria prática humana domínio da natureza. Isso na história ocorreu essencialmente em duas etapas. Em primeiro lugar, na chamada "fase mágica" da civilização, por meio da manipulação organizada da mímesis. Em segundo lugar, na fase histórica, através da práxis racional ou mítica, cuja principal manifestação aparece na forma de vida do trabalho, que já se encontrava na Grécia Antiga. Daí um dos motivos de os autores demonstrarem que a epopeia de Homero constitui a prefiguração do fenômeno moderno da reificação, uma vez que nessa obra mito e exploração são sinônimos.

Dispensa dizer que, para os referidos autores, ainda estamos vivendo nessa segunda etapa, ainda que, de modo algum, tenhamos superado os resquícios primitivos da fase mágica, sobretudo no âmbito cultural, que reproduz aquele elemento primitivo da selvageria inerente à necessidade desenfreada de autopreservação, como deixa transparecer o trecho a seguir, retirado do capítulo sobre a indústria cultural: "A vida no capitalismo tardio é um contínuo rito de iniciação. Todos têm de mostrar que se identificam integralmente com o poder de quem não cessam de receber pancadas" (ADORNO, HORKHEIMER, 2013, p.127).

Tendo em vista essa breve contextualização da Dialética do Esclarecimento, cabe aqui explicitar o que, afinal, os autores entendem por esclarecimento: 


\begin{abstract}
No sentido mais amplo do progresso do pensamento, o esclarecimento tem perseguido sempre o objetivo de livrar os homens do medo e de investi-los na posição de senhores. Mas a terra totalmente esclarecida resplandece sob o signo de uma calamidade triunfal. O programa do esclarecimento era $\mathrm{o}$ desencantamento do mundo. Sua meta era dissolver os mitos e substituir a imaginação pelo saber (ADORNO; HORKHEIMER, 2006, p.17).
\end{abstract}

$\mathrm{Na}$ citação acima aparece o conceito de desencantamento (Entzauberung), que possui uma relevância significativa para a compreensão da dialética do esclarecimento, ainda que não constitua a única chave de interpretação da mesma. Tal termo, longe de ter um significado monolítico, apresenta uma ambiguidade que será explorada por Adorno e Horkheimer ao longo da obra, qual seja a de simbolizar a quebra do feitiço e ao mesmo tempo a decepção com tal quebra (DUARTE, 1997, p.45). Os autores notam que com enfraquecimento cada vez maior das imagens religiosa-metafísicas de mundo em decorrência do próprio processo de racionalização ocidental, amplamente investigado por Max Weber ${ }^{8}$, o que se verificou foi o contrário do esperado de um mundo racionalizado: "A mitologia invadiu a esfera profana"( ADORNO; HORKEHIMER, 2006, p.35), e a arte não foi substituída nem pela ciência, nem pela moral, nem pelo direito, mas pela fé incondicional nas capacidades redentoras de uma razão que se afastava cada vez mais de sua base natural e instintiva, gerando uma vez mais uma irrefletida dominação do homem pelo próprio homem. Por isto que em certa altura da obra os autores ousam afirmar, na contramão de todas as ideologias que proclamam o progresso na história: "Toda desmitologização tem a forma da experiência inevitável da inanidade e superfluidade dos sacrifícios" (ADORNO; HORKHEIMER, 2006, p. 53).

\title{
Da distinção entre Pré e Proto-História
}

Tendo reconstruindo algumas das principais linhas de força da Dialética do Esclarecimento mister se faz apresentar a distinção entre Pré e Proto-História, crucial para o entendimento da presente pesquisa. Protohistória é a tradução para o termo alemão "Urgeschicte", formados pelo prefixo " $U r$ ", que remete para uma gama de ideias, todas relacionadas com uma gênese histórica, entre quais se situam as palavras "origem", "inicialmente" e "primeira característica". Por outro lado, a palavra "Geschichte" significa história no sentido não ficcional do termo. Juntas, "Urgeschichte" remete para uma dimensão de temporalidade radical, de

${ }^{8}$ Com base em Max de Weber, Habermas define a racionalização como "aquele processo de desencantamento ocorrido na Europa que, ao destruir as imagens religiosas do mundo, criou uma cultura profana" (HABERMAS, 2000, p.3). 
devir-ser, de um processo de desintegração de determinado objeto e sua relocação no decurso da história. Saber isto nos dá uma pista sobre o seu uso por Adorno, bem como da centralidade desse conceito na visão de alguém que respeitava o devir histórico como núcleo da ideia de verdade, porém se mostra estreita em vista da sua apropriação pela linguagem filosófica. O texto de Adorno lhe confere um novo significado que nada tem a ver com o uso habitual de "Urgeschichte" como origem histórica de "algo". Protohistória designa, portanto, a variação, bem como os usos e diferentes sentidos que algo tomou ao decorrer de sua existência e não a mera descrição factual de acontecimentos na história.

Deste modo, qualquer redução da proto-história adorniana à genealogia nietzschiana é ilusória. Na genealogia nietzschiana as variações e mutações de algo ao longo de sua existência são qualitativas, havendo uma descontinuidade entre o que algo significava e ao que veio significar. Em Adorno ocorre algo distinto, "a proto-história de algo" busca a sua existência virtual antes de se concretizar plenamente. Ao invés do que faz Nietzsche, de ver como a identidade de um termo ao longo da história acaba enganando e escamoteando sua alteridade ao subtrair a particularidade por sua suposta coerência, Adorno chama atenção para o continuum, para a persistência, mesmo que tímida e velada, desse "algo" que não é perceptível prima facie. Assim, quando tomamos "Urgeschichte der Moderne" proto-história da modernidade - trata-se de ver aspectos desta modernidade antes mesmo de seu aparecimento no período convencionado como modernidade. Como se os fenômenos os quais hoje designamos como estritamente modernos, por exemplo, o advento do capitalismo industrial, já estivesse existido potencialmente na era antiga, como cripto-capitalismo. O mesmo ocorre com qualquer termo que se situe ao lado de Urgeschichte, tais como pro-história do fascismo ou proto-história da dominação.

$\mathrm{Na}$ verdade, Adorno nunca deu uma definição precisa do significado de proto-história, algo que, de fato, pode contradizer seu próprio procedimento. O que estamos fazendo aqui é abstrair do seu próprio procedimento tal como aparece na Dialética do Esclarecimento - o aparecimento mais modelar de proto-história, proto-história da subjetividade $^{9}$, mediante o exame da figura de Ulisses, o protótipo do sujeito moderno. Como Adorno só fez um uso completo na Dialética do Esclarecimento da proto-história como proto-história da subjetividade podese questionar se é possível empregar a proto-história em outros contextos, separada da subjetividade. A pergunta que fica é: não seria forçado aplicar a proto-história como uma espécie de método arqueológico para outros casos além daquele único que Adorno fez uso? Talvez o fato de "Urgeschichte" aparecer de forma relâmpago em outros escritos seus confirme, de maneira

9 "É a saudade de casa que desfecha as aventuras por meio das quais a subjectividade (cuja proto-história é narrada pela Odisseia) escapa ao mundo primitivo" (ADORNO; HORKHEIMER, 2006, p. 69). 
um tanto inusitada, a nossa própria suspeita sobre o tema, qual seja de que Adorno estaria seguindo, na melhor tradição marxista, um modelo de pensar dialético no qual aquilo que precisa ser imediatamente criticado nunca aparece de modo imediato, como se aquilo que fosse fundamental combater não tivesse o direito de merecer a nossa atenção imediata, tendo que paralelamente ser criticado para o bem mor da própria verdade, a fim de evitar a própria positivação desta aparência que se apresenta como a verdadeira.

A proto-história em seu sentido mais amplo do termo demonstra, antes de tudo, a persistência de um princípio que atravessa a história: o princípio de identidade ou da dominação da natureza. Mas também demonstra que a história possui em si os meios para sua libertação desses mesmos princípios. Desta forma, a proto-história tem um caráter dialético: "Não há duas verdades, a da sociedade existente e a da outra sociedade; a verdade desta é inseparável do movimento real no interior do existente, e de cada um de seus movimentos" (ADORNO, 2001, p.89). A liberação é coexistente com o princípio que o subjuga, não algo que o antecede ou mesmo lhe sucede, como um princípio originário que foi perdido e que necessita ser redescoberto. Na Dialética do Esclarecimento fica claro este movimento dialético "do movimento real no interior do existente". Cada etapa da civilização apresenta uma intensificação dos meios de dominação sobre a humanidade, porém, ela também apresenta em seu interior a promessa de algo qualitativamente diferente, como no episódio dos lotófagos, os comedores de lótus. Estes representam já o "esquecimento e a destruição da vontade" e isso remete ao caráter narcótico do efeito da ingestão do lótus. Embora a felicidade fruto da ingestão do lótus seja falsa, ela não deixa de conter o seu contrário como promessa:

O hábito de comer flores - que ainda se pratica à sobremesa no Próximo Oriente e que as crianças europeias conhecem das massas assadas com leite de rosas e das violetas cristalizadas é a promessa de um estado em que a reprodução da vida se tornou independente da autoconservação consciente e o prazer de se fartar se tornou independente da utilidade de uma alimentação planejada. A lembrança da felicidade mais remota e mais antiga, que desperta o sentido do olfato, ainda está intimamente ligada à proximidade extrema da incorporação (ADORNO; HORKHEIMER, 2006, p.60).

Esse trecho, além de demonstrar o caráter dialético do processo civilizatório, encaminha-nos para outra conclusão no tocante a proto-história - seu traço materialista. Isso não remete somente a óbvia filiação aos pressupostos marxistas da teoria crítica, mas sim como os próprios acontecimentos da história ganham concreção e são representados.

Em sua discussão epistolar com Benjamin, a propósito do ensaio sobre Baudelaire, Adorno discorre sobre os dois inconvenientes a se evitar: 
“A encruzilhada de magia e positivismo" (ADORNO; BENJAMIN, 2012, p.403). Por um lado, um texto exclusivamente metafórico, que manuseie suas figuras de modo idealista, portanto, de cima, tende à magia. Por outro lado, um texto que faça do dado empírico algo absoluto e do qual dispensa toda interpretação diante de sua auto-evidência cai num positivismo estreito, o qual acredita que o mundo externo ao sujeito é idêntico à representação deste mundo pelo sujeito. Isso nos ajuda a compreender adequadamente a proto-história presente na Dialética do Esclarecimento através da interpretação da Odisseia. Adorno e Horkheimer não tratam as narrativas da Odisseia como simples exemplos do processo civilizatório, uma imagem privilegiada que traduziria nossa condição histórica atual. Eles dizem isso e mais: a Odisseia de Homero é um documento histórico privilegiado, não só do tempo do sujeito histórico Homero e sim da história que o precedeu. Todavia a proto-história de algo pode dormitar sobre os mais inusitados objetos: uma revista de variedades ou um acorde musical pode revelar a história sedimentada no interior de si (ADORNO, 2011, p.38). Essa história sedimentada, porém, só pode emergir da interpretação e não da mera descrição, assim como a interpretação deve se ater ao conteúdo material de onde ela provém e não ser retirada do seu contexto.

A proto-história adorniana demonstra uma evidente predileção por certos objetos de interpretação em detrimento de outros. Ao invés de se ater aos acontecimentos históricos ditos relevantes, que supostamente causaram rupturas na história, como a "descoberta" da América ou a Revolução Francesa, Adorno se detém nas manifestações da história presentes no interior da cultura. Essa predileção não é de caráter subjetivo, como seu interesse pela arte poderia suscitar, e sim algo que deve ser compreendido em duas frentes teóricas. Em primeiro lugar, a partir daquilo que Adorno afirma na Teoria Estética, ao dizer que a arte um sismógrafo privilegiado para compreender a história ${ }^{10}$, tendo em vista que ela consegue não só assimilar o sofrimento em seu material, o perigo de seu auto-aniquilamento no momento de sua criação, como também a imagem virtual de um novo mundo. Em segundo lugar, a partir do próprio comportamento do pensamento de Adorno ao ignorar as rupturas ou grandes acontecimentos. Ao fazer isto acaba por intensificar umas das ideias centrais por detrás da noção de proto-história: o continuum ainda não foi rompido na história. Tal afirmação é embasada, entre outros fenômenos, na contínua ocorrência do sofrimento. Assim, o que dá concreção aos conceitos e à proto-história, como se viu, não são os grandes acontecimentos, nem os métodos empíricos científicos, e sim as diferentes formas de sofrimentos e suas manifestações nos mais variados objetos e sujeitos.

\footnotetext{
10 "Enquanto esforço mimético contra o interdito, a arte procura proporcionar a resposta e, no entanto, porque carece de juízo (Urteil), não a fornece; deste modo se torna enigmática, como o horror do mundo primitivo, que se modifica, mas não se esvanece; toda a arte permanece o seu sismograma" (ADORNO, 2013, p.197).
} 
O contraponto polêmico de mito e esclarecimento é manifesto. Porém, como faz notar Guido de Almeida, tradutor da obra para o português, traduzir "Aufklärung" como esclarecimento tem a vantagem de comportar a ambiguidade original do termo, amplamente explorada pelos autores no decorrer do livro: esclarecimento diz respeito tanto à filosofia das luzes - iluminismo, em seu sentido histórico-filosófico - como no sentido coloquial da língua alemã, na qual se traria de um processo pelo qual o indivíduo vence as trevas da ignorância e do preconceito em questões de ordem prática, tais como religião, política, sexualidade, etc. (ADORNO; HORKHEIMER, 2006, p.7). Essa definição dada por Guido de Almeida ao termo Aufklärung só vem a confirmar a que o próprio Adorno deu ao termo em outra circunstância ${ }^{11}$. Desta forma, quando Adorno e Horkheimer dizem que "o mito já é esclarecimento e o esclarecimento acaba por reverter à mitologia" (ADORNO; HORKHEIMER, 2006, p.15) não só estão apontando o fracasso do projeto iluminista do qual não querem abandonar, como estão assinalando a linha pela qual são interligados o mais antigo e o mais atual. Aqui se encontra, portanto, outro aspecto significativo da protohistória: a justaposição do arcaico e do moderno.

A justaposição entre o arcaico e o moderno tem uma função bem precisa na proto-história. Kant pôs a história até a modernidade sob a suspeição de "menoridade" da qual o Esclarecimento, enquanto projeto, teria a pretensão de romper. A intenção da justaposição entre o arcaico e o moderno em Adorno é mostrar que a suspeição de Kant quanto à história estava correta, entretanto o projeto da Aufklärung "tendia em direção àquilo que denunciava" (ADORNO, 2009, p.48). Portanto, a modernidade permanecia irrealizada e, além disso, mais um episódio dentro do continuum da história. Assim, as figuras arcaicas, símbolos da barbárie, da violência selvagem, aparecem naquilo que há de mais avançado, mais atual. Nesse ponto, podemos dizer, tal como o fez Alex Thomson (THOMSON, 2006, p. 136), que Adorno e Horkheimer são devedores da Genealogia da Moral de Nietzsche. Isso porque tanto Nietzsche quanto os autores da Dialética do Esclarecimento apresentam a história subterrânea da civilização. Por trás dos mais avançados discursos éticos e morais se encontram sublimados uma violência insuspeita. Evidentemente que isso não se aplica somente aos discursos morais e éticos, e sim a cultura em todas as suas manifestações.

O termo Urgeschichte, traduzido como proto-história por Guido Antonio de Almeida, poderia muito bem ser posto, como nas traduções da

\footnotetext{
11 “Ilustración \{Aufklärung) es el propósito de este trabajo [El concepto de inconsciente em la doctrina trascendental del alma; j.s.s; r.r.a], Ilustración en el doble sentido del término", es decir, como esclarecimiento de un problema conceptual en primer lugar, pero también, en segundo lugar, como meta en el amplio sentido que la historia confiere a este término, a saber: como destrucción de teorías dogmáticas para erigir en su lugar teorías basadas en la experiencia y absolutamente ciertas para la experiência”(ADORNO, 2010, p. 11).
}

A estética dos extremos: notas sobre a relação entre a arte rupestre e a reprodutibilidade técnica em Theodor Adorno - Jéverton Soares dos Santos; Robson da Rosa Almeida 
Dialética do Esclarecimento em espanhol e inglês ${ }^{12}$, como sinônimo de Vorgeschichte - pré-história. Mesmo que o prefixo "Ur" e "Vor" tenham significados distintos, no alemão as duas palavras - Urgeschichte e Vorgeschichte - podem aparecer com sentidos semelhantes. Porém, a distinção se mostra precisa quando se percebe o peso específico desses termos dentro da obra e do pensamento adorniano. Se proto-história tem quase a conotação de um método histórico, pré-história parece ser a conclusão deste método.

Pré-história é geralmente tida como um período da própria história que remete a antes do surgimento da escrita ${ }^{13}$. No entanto, a pré-história da qual Adorno fala tem um sentido bem diferente: pré-história é o período anterior ao começo da história, ela não se encontra dentro da história como um período seu, pois a história seria de uma essência oposta daquela da préhistória. A história seria para Adorno o mesmo que a efetivação da utopia enquanto que a pré-história seria o seu contrário, um momento sem tempo, sem história - o sempre-idêntico. Assim sendo, não só os demais períodos como antiguidade, Idade Média, modernidade, acabariam se diluindo em meio a essa pré-história, como a história como um todo não seria nada mais do que a pré-história camuflada de história. Esse ponto não está tão claro e explícito no seu conjunto de obras reunidas. Porém, ele aparece com maior clareza em uma troca de correspondência de Adorno a Benjamin:

Eu diria assim: que para nós [Adorno e Benjamin; j.s.s.; r.r.a] o conceito de era histórica é meramente inexistente (da mesma maneira que não conhecemos decadência e progresso no sentido próprio que você destrói nesse contexto [o ensaio sobre o Kafka; j.s.s.; r.r.a]), e só apreendemos a era histórica como extrapolação do presente petrificado (ADORNO, BENJAMIN; 2012, p.130).

Como dito no final da citação Adorno até poderia de vez em quando fazer referência a alguma época ${ }^{14}$, porém, sempre como uma "extrapolação do presente petrificado", isto é, por detrás da fisionomia de uma dada época

\footnotetext{
12 A tradução espanhola traduz indiferentemente Vorgeschichte e Urgeschichte como prehistoria (ADORNO; HORKHEIMER,1998, p.57). A tradução inglesa diferencia algumas vezes utilizando ora earliest history (ADORNO; HORKHEIMER, 2012. p.43), primal age (ADORNO; HORKHEIMER, 2012. p.50) e a mais recorrente entre elas prehistory (ADORNO; HORKHEIMER, 2012. p.46, 50, 55, 148) para denominar Urgeschichte, o que fica confuso porque em todas as ocorrências de Vorgeschichte é traduzida também como prehistory.

13 “A história estuda o passado humano, a partir da invenção da escrita, dedicando-se superficialmente à pré-história - período anterior ao aparecimento da escrita" (RAMOS, 1977. p.16).

${ }^{14}$ Por exemplo: "Contudo, a técnica dodecafônica, pela primeira vez desde fins da Idade Média e com um domínio dos meios incomparavelmente maior, cristalizou um estilo polifônico genuíno" (ADORNO, 2011, p. 76).
}

A estética dos extremos: notas sobre a relação entre a arte rupestre e a reprodutibilidade técnica em Theodor Adorno - Jéverton Soares dos Santos; Robson da Rosa Almeida 
se esconde a extrapolação do presente petrificado, seu princípio elevado à potência, novamente o sempre-idêntico.

A prova incontestável de que, para Adorno e Horkheimer, a préhistória é mais que um período histórico, que ela é o próprio presente do qual fazemos parte, situa-se no final do excurso II da Dialética do Esclarecimento:

\begin{abstract}
A essência da pré-história [Vorgeschichte] é o aparecimento do horror supremo no detalhe. Por trás do cômputo estatístico das vítimas do progrom, que inclui os fuzilados por misericórdia, oculta-se a essência que somente surge à luz na descrição exata da exceção, ou seja, da mais terrível tortura. Uma vida feliz num mundo de horror é refutada como algo de infame pela mera existência desse mundo (ADORNO; HORKHEIMER, 2006, p.97).
\end{abstract}

Assim, a essência da pré-história seria "o aparecimento do horror supremo no detalhe". Desta forma, a pré-história não significa um período dentro da história cuja característica essencial seja a ausência de escrita. Ela ultrapassaria seu próprio limite temporal onde quer que apareça o "horror supremo no detalhe", ou melhor, onde quer que o tempo esteja ausente. Assim, o conceito de pré-história (Vorgeschichte) se afasta completamente da proto-história (Urgeschichte). Enquanto pré-história se entrelaça com a história com o anseio de anular esta última, ou seja, a história como sendo, na verdade, a pré-história, por outro lado a proto-história pretende designar o arcaico, o primitivo, o bárbaro, que se esconde por trás da máscara do presente como sendo o ético, o avançado e o civilizado.

\title{
A arte rupestre e a reprodutibilidade técnica
}

É relevante notar que a concepção de história, vista pelas categorias Urgeschichte e Vorgeschichte, quando colocada sob a perspectiva da arte ganha outra significação. As obras de arte são como exceções dentro da história, um resquício do que há de realmente histórico no sentido de temporalidade em oposição à ausência do tempo, à aparência de tempo. Isso não passou despercebido por Fredric Jameson que interpretou a experiência estética em Adorno como um momento de exceção na história, ou melhor, o momento verdadeiramente histórico, o instante utópico: “A experiência estética também nos conduz de volta à história - à história do capitalismo do qual a obra emergiu, e à constelação de classes e racionalidade instrumental que é seu conteúdo semântico e torna possível sua dimensão utópica" (JAMESON, 1997, p.291). As obras de arte têm seu elemento intrahistórico, ligados aquele momento absolutamente moderno o qual emergem - "à constelação de classes e racionalidade instrumental"- entretanto, seu conteúdo aponta para além de seu instante de aparecimento - "sua dimensão utópica". Por essa razão, as obras de arte estariam na pré-história 
(Vorgeschichte), na medida em que refletem esta realidade social problemática, ao mesmo tempo em que prefigurariam outra realidade fora dessa pré-história. Mais claro fica isso à luz de sua última obra publicada, Teoria Estética:

\begin{abstract}
Que as obras de arte, como mônadas sem janelas, 'representem' o que elas próprias não são, só se pode compreender pelo fato de que a sua dinâmica própria, a sua historicidade imanente enquanto dialética da natureza e do domínio da natureza não é da mesma essência que a dialética exterior, mas se lhe assemelha em si, sem a imitar (ADORNO, 2013, p.18).
\end{abstract}

Enquanto algo empírico, a obra de arte é um ente em meio aos demais entes, por essa razão elas representam "o que elas próprias não são", ou seja, algo que ultrapassa seu caráter existente. Quando ela reflete esse mesmo existente não é uma mera reprodução da história, pois "enquanto dialética da natureza e do domínio da natureza não é da mesma essência que a dialética exterior". A obra de arte em seu caráter monadológico permite-se isolar da realidade, como algo distinto, mas que, em seu absoluto fechamento, consegue refletir o todo de maneira fidedigna. Assim, as obras de arte ficam a meio caminho da pré-história e da história sem nunca chegar a termo ao qual das duas realmente pertence, já que da história verdadeira elas não são mais que um simulacro - promesse du bonheur -, e da préhistória ainda estão ligadas ao contexto de onde se inserem enquanto obra e crítica.

Já em relação à proto-história (Urgeschichte), as obras de arte intensificariam ainda mais esta categoria. Aquilo que havíamos designado como o caráter dialético da proto-história tem nas obras de arte seu melhor exemplo. A proto-história enquanto dialética da Aufklärung tem em seu movimento contínuo tanto seu enredamento quando sua libertação imanente ao processo histórico. Em todas as manifestações da cultura é na arte onde ela mantém sua promessa intocada. Essa promessa seria tão antiga quanto o princípio negativo que rege a história. Desta forma, a proto-história do Esclarecimento pode ser acompanhada por sua contraparte nas obras de artes: "A ânsia de salvar o passado como algo de vivo, em vez de utilizá-lo como material para o progresso, só se acalmava na arte, à qual pertence a própria História como descrição da vida passada" (ADORNO; HORKHEIMER, 2006, p.38-9). Salvando o passado, a arte não só representaria um registro preciso da história como também seria testemunha da promessa que ela acompanha em seu movimento.

Proto-história significa também a dialética do arcaico e do moderno. As obras de arte são elas mesmas produtos da proto-história. Sua autonomia foi conseguida por intermédio de seu constante e ininterrupto 
processo de secularização. Sua origem teológica é rompida, mas persiste algo desta origem arcaica:

Pela sua ruptura inevitável com a teologia, com a pretensão absoluta à verdade da redenção, secularização sem a qual ela jamais se teria desenvolvido, a arte condena-se a outorgar ao ente e ao existente uma promessa, que, privada da esperança num Outro, reforça o sortilégio de que se quis libertar a autonomia da arte (ADORNO, 2013, p.12).

A "esperança num Outro", cuja raiz é teológica, mantém-se na arte mesmo após a sua secularização ao longo do processo em que culmina na autonomia da esfera artística. Dessa forma, o elemento arcaico regressa em toda obra de arte. As obras de arte têm, porém, em seu polo oposto o seu caráter absolument moderne (ADORNO, 2013, p.291). Para Adorno, o absolutamente moderno se concretiza mediante os procedimentos técnicos. Isso fica evidente quando Adorno traduz moderno como algo que transcende o momento histórico compreendido como modernidade:

Sem dúvida, a noção de Moderno remonta cronologicamente muito atrás do Moderno enquanto categoria filosóficohistórica; mas esta não é cronológica. É antes o postulado rimbaudiano da consciência mais progressista, na qual os procedimentos técnicos mais avançados e mais diferenciados se interpenetram com as experiências mais avançadas e mais diferenciadas (ADORNO, 2013, p.59).

O progresso do material estético tem como produto assimilar a história de seu material e ultrapassar essa mesma história. Assim, a obra de arte obtém seu estatuto de absolutamente moderno por meio da tradição e negando essa mesma tradição. Para Adorno, seria nessa negação do antigo em que esse mesmo antigo retorna de modo mais insistente no moderno: " $\mathrm{O}$ Novo obedece à pressão do Antigo que precisa do Novo para se realizar" (ADORNO, 2013, p.43). Se na proto-história da modernidade a dialética do arcaico e do moderno possui um traço negativo, nas obras de arte o arcaico e o moderno não só refletem essa negatividade da proto-história como apontam para a sua superação. Entretanto, essa dialética do arcaico e do moderno nas obras de arte, como Adorno mesmo sugere, não pode ser realizado de modo abstrato: "A tradição não deve negar-se abstratamente, mas criticar-se de modo não ingênuo, segundo a situação presente: o presente constitui assim o passado" (ADORNO, 2013, p.70). O caráter material da obra de arte, onde a negação da tradição deixa de ser abstrata e passa a ser determinada, é realizado por meio do procedimento técnico. Agora, porém, o que Adorno entende por procedimento técnico possui uma variedade de significações, que ganha em complexidade graças a sua herança marxiana e ao diálogo com Walter Benjamin. Progresso do material estético e procedimentos técnicos necessitam, portanto, de um 
aprofundamento no qual a proto-história antecipam, na origem das obras de arte, grande parte deste problema sem limitar seu desenvolvimento.

Em "A obra de arte na era de sua reprodutibilidade técnica", Walter Benjamin realiza uma inequívoca distinção entre a obra de arte aurática e a obra de arte tecnológica. Para Benjamin, com advento da modernidade criou-se a necessidade de possuir o objeto, seja em sua imagem ou na sua cópia - sua reprodução - provocando a destruição da aura, isto é, o caráter hic et nunc inerente ao objeto particular. Segundo o nosso autor: "[a aura, j.s.s] é uma teia singular, composta de elementos espaciais e temporais: a aparição única de uma coisa distante, por mais perto que ela esteja" (BENJAMIN, 2012, p.184). O imperativo de "orientar a realidade em função das massas e as massas em função da realidade" passa ser um juízo decisivo para entender a forma de percepção da coletividade humana inerente à fase moderna. A reprodução mecânica reforça a própria insistência do homem moderno de tentar captar o semelhante no diferente, a unidade na diversidade, a ordem no caos. A existência massiva ou serial da reprodutibilidade técnica se contrapõe, aqui, com a existência única da aura. A primeira atualiza o objeto reproduzido ao mesmo tempo em que liquida o valor tradicional do patrimônio da cultura inerente à existência aurática. $\mathrm{O}$ decisivo nesse processo é a cada vez maior liquidação do sujeito, ao menos da subjetividade na constituição da obra de arte tecnológica. Mesmo assim o filósofo do anjo está convencido de que a origem das obras de arte está no culto, já que, a seu ver, elas surgiram a serviço de um ritual, que no início era mágico e depois passou a ser religioso, algo que oferece para toda a obra arte autêntica um fundamento teológico, mesmo nos casos onde ela é confessadamente profana e secular: "O valor único da obra de arte autêntica tem sempre um fundamento teológico, por mais mediatizado que seja: ele pode ser reconhecido, como ritual secularizado, mesmo nas formas mais profanas do culto do belo" (ADORNO, 2012, p.186).

A prática mágica de reproduzir um objeto é, para Benjamin, restrita por seu valor de culto. Quer dizer que as imagens ainda não haviam se tornado autônomas de seu uso prático e que, ao mesmo tempo, esse mesmo valor de culto mantém-se ainda na arte secularizada. A reprodutibilidade, enfim, destruiria esse valor de culto graças ao valor de exposição, ou seja, quando a imagem deixa de ser vista ocasionalmente por uma pessoa - o sacerdote - e passa a ser vista por um número cada vez maior de pessoas. Já para Adorno, as imagens primitivas das cavernas ou as manifestações mais antigas das representações imagéticas ultrapassam seu valor de culto pela magia:

Se o comportamento estético, antes de toda objetivação, se separou das práticas mágicas, mesmo de maneira muito vaga, e conserva desde então um resquício, como se a mimese remontando ao estrato biológico e tendo perdido toda função tivesse sido conservada, prelúdio da forma segundo a qual a

A estética dos extremos: notas sobre a relação entre a arte rupestre e a reprodutibilidade técnica em Theodor Adorno - Jéverton Soares dos Santos; Robson da Rosa Almeida 
superestrutura se revoluciona mais lentamente do que a infraestrutura (ADORNO, 2013, p. 500).

Está passagem possui duas referências evidentes ao texto sobre a reprodutibilidade técnica de Benjamin. A primeira referência é sobre os aspectos que, segundo Benjamin, após a secularização das imagens de seu uso mágico seriam elevadas pelas formas do uso profano do culto ao Belo. Para Adorno, mesmo no uso mágico, as imagens já possuíam os resquícios de sua posterior objetivação no comportamento estético - "mesmo que de maneira vaga". Não foi após a sua autonomia da magia e depois da religião que a arte conseguiu sua objetivação. Ela possuía virtualmente em sua proto-história essa objetivação.

A segunda referência alude ao desenvolvimento da arte naquele sentido marxista de infraestrutura (unterbau) e superestrutura (Überbau). Nesse ínterim, Adorno não descorda de Benjamin. Ele apenas usa essa referência à introdução do ensaio sobre a reprodutibilidade técnica de forma irônica. Isso porque Benjamin diz que "tendo em vista que a superestrutura se modifica mais lentamente que a base econômica, as mudanças ocorridas nas condições de produção precisaram mais de meio século para refletir-se em todos os setores da cultura" (BENJAMIN, p.165). Benjamin quer dizer com isso que as mudanças na técnica demoraram para refletir-se em transformações qualitativas nas obras de arte. Mas quando Adorno diz "prelúdio da forma segundo a qual a superestrutura se revoluciona mais lentamente do que a infraestrutura" está querendo dizer que a própria magia deveria ser vista pela mesma perspectiva que a reprodutibilidade técnica em nosso tempo. Isto é, o uso das imagens pela magia não acompanhava seu desenvolvimento material, ou melhor, ao nível de dominação da natureza. As imagens remetiam a um período anterior, nas quais elas ainda estavam diretamente ligadas ao seu conteúdo mimético. Portanto, o uso das imagens pela magia ainda possuía resquícios dessa mímesis, e por isso, também reservas em relação ao processo civilizatório.

Adorno critica a tendência de se pretender eliminar os enigmas arcaicos a partir de uma explicação estritamente religiosa. Mas concorda com a distinção benjaminiana entre a religião e a magia. Segundo nosso autor, a magia está ao serviço direto dos meios de subsistência, diferentemente da religião que deveria fornecer uma alternativa espiritual para a dureza do mundo físico (ADORNO, 2013, p.496/ ADORNO, 1990, p.482). A religião, assim como a arte, propicia ao homem uma experiência teórica e sensorial que faz com que ele fuja parcialmente da dureza da existência imediata ou da necessidade material. De acordo com o filósofo, somente uma humanidade liberta da preocupação com a necessidade material conhecerá o caráter ideológico da negação dessa necessidade, tão propagada pela cultura capitalista de massa. Por isso que o frankfurtiano 
afirma que o "eu" só pode ser pensado em sua plenitude por meio de conceitos teológicos, e não por meio de uma ontologia, já que a busca pelo fundamento ontológico - mesmo que não voluntariamente - está baseada no primado do interesse concreto:

Do eu não se deveria falar como de um fundamento ontológico, mas quando muito apenas em termos teológicos, em nome da imagem e semelhança de Deus. Quem se aferra ao Eu puro e se desembaraça dos conceitos teológicos contribui para legitimar a diabólica positividade, o interesse nu e cru (ADORNO, 1993, p.136).

Por outro lado, Adorno não endossa a tese benjaminiana de uma separação inequívoca entre a obra de arte tecnológica e a obra de arte aurática. Para o frankfurtiano, qualquer obra destinada à pluralidade mesmo a arte rupestre - já contém virtualmente a ideia de reprodutibilidade técnica (ADORNO, 2013, p.59/ ADORNO, 1990, p.56). Que pese, aqui, a diferença entre pluralidade (ein vielen zu bestimmtes) e plurovacidade (Mehrdeutigkeit). Enquanto que a pluralidade se refere ao caráter serial da produção massiva, a plurovacidade é uma característica típica da era préhistória, uma vez que a ideia moderna de sujeito está inevitavelmente comprometida com a noção de univocidade (Eindeutigkeit): "A plurivocidade [Mehrdeutigkeit] não deve, ou não apenas, ser imputada à estreiteza do conhecimento [Erkenntinis]; é antes peculiar à própria préhistória [Vorgeschichte]. A univocidade só existe depois que a subjetividade se manifestou (ADORNO, 2013, p. 497/ ADORNO, 1990, p.482)".

Convém assinalar que o excurso "Theorien über den Ursprung der Kunst" é certamente o lugar da obra Teoria Estética no qual Adorno realiza um verdadeiro diálogo com a ciência arqueológica de sua época. No entanto, antes de qualquer coisa, faz-se mister ter em mente algumas estimativas arqueológicas que poderão ser úteis para a discussão doravante (Cf. Figura 1): 


\section{Timeline of Prehistory}

4 million years ago: Australopithecus appears

From 2 million years ago until 10,000 B.C: Paleolithic Age

1,600,000 years ago: Homo erectus appears

100,000 years ago: Neanderthal and Homo sapiens sapiens appear

32,000 years ago: Homo sapiens sapiens (modern humans) are the only type of humans

From 10,000 to 9000 B.C. (to 4000 B.C. in Europe): Mesolithic Age

From the Mesolithic to around 3000 B.C.: Neolithic Age

From 3000 to 1100 B.c.: Bronze Age

From 1100 B.C. to the present: Iron Age

Figura 1: Linha do Tempo da Pré-História ${ }^{15}$.

Dispensa dizer que as datas presentes nesse quadro não devem ser consideradas exatas. São estimativas e como tais estão sujeitas à controvérsia, à discussão. No entanto, elas são capazes de nos dar certa noção do tamanho da dificuldade subjacente ao tema. O enfoque de Adorno sobre a arte rupestre - que é o enforque da maioria dos trabalhos arqueológicos sobre o assunto - concentra-se principalmente no período paleolítico, que como tal é capaz de englobar quase três milhões de anos.

Uma das teses que Adorno procura refutar neste excurso é per se problemática, não obstante ela possuir adeptos tanto na filosofia quanto na ciência. Trata-se da crença de que só é possível apreender a essência de um fenômeno depois de se desvendar a sua origem. No caso da estética filosófica, ela se manifesta mediante a suposição de que existe um sentido teleológico inerente às primeiras manifestações artísticas da pré-história. Como se houvesse um significado supra-histórico inerente a algo préhistórico, nesse caso a arte rupestre. Adorno observa que falar de origem fora de todo elemento temporal é trair a própria temporalidade inerente ao sentido "literal" de origem. No caso da disciplina estética, a confusão que ocorre é maior ainda em virtude do próprio caráter de "ter-estado-em-devir da arte" [Gewordensein von Kunst], isto é, o fato de ser impossível defini-la sem, de um lado, saber o que ela foi e o que se tornou e, por outro lado, sem projetar o que ela pretende ser e o que ainda poderá ser (ADORNO, 1990, p.12/ ADORNO, 2013, p.14). Como enfatiza o nosso autor: "Mas o caráter da arte, dela ser produto do devir [des Gewordenen], proíbe que ela se reduza à sua origem [Ursprung] pré ou proto-histórica [ vor - oder frühgeschichtlichen]" (ADORNO, 1990, p.480/ ADORNO, 2013, p.493).

${ }^{15}$ In: TERZI, Marinella. Prehistoric Rock Art. Chicago: Child Press, [S.I], p. 10. 
Tal elemento não permite a adoção de um momento, seja ele histórico ou ontológico, como sendo o mais decisivo para compreensão do enigma da arte. A pretensa autenticidade das obras mais antigas não pode eliminar uma constrangedora situação: que elas são fontes de confusão, jamais de clareza (ADORNO, 1990, p.480/ ADORNO, 2013, p.493). Nada melhor do que vislumbrar uma das obras mais conhecidas a este respeito, a Vênus de Willendorf, que provoca discussões sobre o seu sentido mais genuíno:
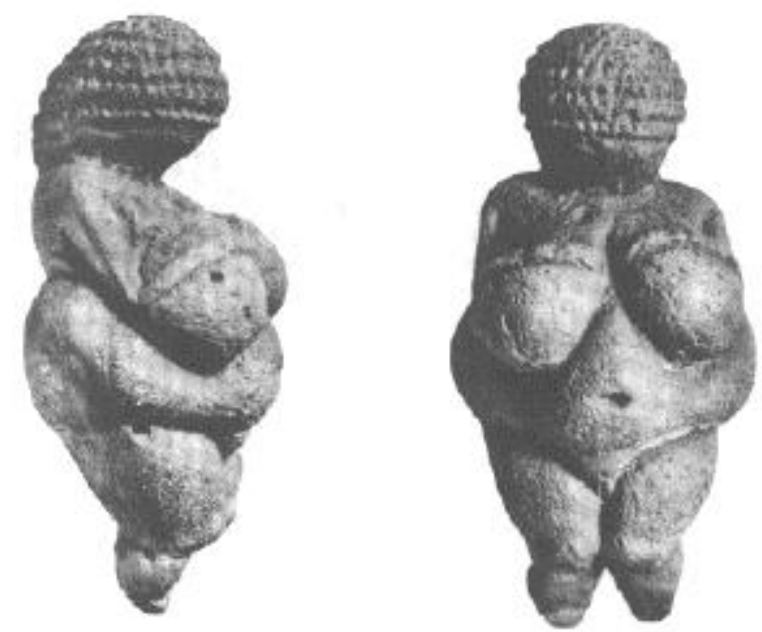

Figura 4: A Vênus de Willendorf. Áustria (+ / - 25000 a.C). (Cf. WILDGEN, 2004, p. $118)$

Dessa forma, é relevante para a discussão da arte rupestre, na análise adorniana, notar que há uma distinção entre o conceito de "Espressione" de Benedetto Croce e o de "Ausdruck" de Adorno. Ambos os termos se traduzem para português como simplesmente "expressão", não obstante possuírem significados distintos, sobretudo no contexto estético aqui examinado. Em Croce, a "Expressione" é uma categoria utilizada para descrever a forma de consciência responsável pela arte enquanto tal. Em uma passagem de sua "Asthetik als Wissenchaft...", citada por Adorno, Croce se utiliza dessa ideia para refutar a postura de se querer apreender o significado da arte a partir de sua origem temporal:

Tendo em vista que esta atividade "intelectual" é o seu [da história ] objeto, pode nela reconhecer [erkennen] o quão é colocar o problema histórico da origem...Se a expressão [ Expression] é uma forma de consciência [ Bewußtseins], como poderá então buscar-se a origem histórica de algo que não é nenhum produto da natureza e que é pressuposto pela história humana[ menschlichen Geschichte]? Como será possível demonstrar a gênese histórica do que é uma categoria, graças à qual se apreende toda a gênese e todo o fato histórico? (ADORNO, 2013, p.494; ADORNO, 1990, p.480-1). 
Segundo Adorno, com afirmações desta natureza, Benedetto Croce introduziu na estética filosófica um nominalismo radical (radikalen Nominalismus), ou seja, ele sobrepôs juízos estéticos sobre realizações artísticas e experiências estéticas. Tal nominalismo pode ser compreendido a partir das próprias palavras de Croce, retirada de uma das suas obras centrais, o livro Essência da Estética:

Nem o artista que produz arte nem o expectador que contempla tem a necessidade de qualquer outra coisa que o universal e o individual, ou melhor, o universal individualizado, atividade artística universal, que é inteiramente comprimida e concentrada na representação de um estado da alma solitário ${ }^{16}$ (CROCE, 2010, p.16).

Contra essa noção idealista de expressão Adorno propõe que ela seja vista a partir de sua concreção mimética, isto é, nos casos que ela literalmente - "expresse" algo - por exemplo, a atitude de chorar - o que faz com essa categoria transcenda a condição de conceito abstrato e que ganhe contornos naturais que superam a condição de mera natura:

Quando o membro de um clã imita o animal totem ou uma divindade temida e nela se transforma, constitui-se a expressão, algo diferente do que o indivíduo é para si. Enquanto a expressão parece fazer parte da subjetividade, é lhe peculiar enquanto alienação o não eu, o coletivo. Quando o sujeito que desperta para a expressão busca a sua sanção, a expressão é já testemunho de uma ruptura. Só com a consolidação do sujeito em autoconsciência é que a expressão se torna autônoma enquanto expressão de tal sujeito, mas conserva o gesto do que se toma alguma coisa (ADORNO, 2013, p.499/ ADORNO, 1990, p.486)

As imagens em sua forma primitiva já seriam um protesto contra o estado de coisas em que nelas emergiriam. Segundo Adorno, o comportamento estético resulta de uma tensão das coisas como elas são e da imagem que se diferencia da realidade. "O comportamento estético é a capacidade de perceber nas coisas mais do que o que elas são; o olhar sob o qual aquilo que é se transforma em imagem" (ADORNO, 2013, p. 501). Nessa tensão jaz algo de heterogêneo que remete à experiência estética que percebe a distinção específica entre imagem e realidade. Através da experiência estética a imagem, por mais que esteja prenhe da realidade de

\footnotetext{
16 "Neither the artist who produces art nor the spectator who contemplates it has need of anything but the universal and the individual, or better, the universal individuated, universal artistic activity, which is all contracted and concentrated in the representation of a single state of the soul".
} 
onde emerge, leva a algo diverso daquilo que existe. A tradução do que existe em imagem é feita por um princípio totalmente distinto daquele que quer dominar o que representa. Ao invés de subestimar o objeto que é representado, a imagem na arte é superestimada: "Só há compreensão quando o conceito transcende o que ele quer apreender. A arte aduz disso a prova; o entendimento que proscreve semelhante compreensão torna-se imediatamente estupidez; falha o objeto porque o subjuga" (ADORNO, 2013, p.502). Na tradução da imagem pela magia, o objeto ainda era tido como algo não totalmente dominado, um objeto de veneração, por isso não subjugado na representação, muito pelo contrário, tendo em vista que as imagens representadas não eram a reificação do objeto representado, ou a transformação do objeto em matéria morta, mas sim a expressão de algo vivo, cheio de experiência:

Talvez não seja irrevalente que os primeiros desenhos das cavernas [Höhlenzeichnungen], cujo naturalismo de boa vontade se reconhece, deem prova de uma extrema fidelidade justamente na representação [Darstellung] do movimento, como se já quisessem - o que Valéry por fim exigia - imitar com minúcia o indeterminado, o que nas coisas não é coisa. Neste caso, o seu impulso não seria o de imitação, não teria sido naturalista, mas desde o início, protesto contra a reificação [Verdinglichung] (ADORNO, 2013, p. 496-7/ ADORNO, 1990, p.482).

Para além dos clichês arqueológicos que tentam reduzir a arte rupestre a credos religiosos ou até mesmo tentando integrar a arte rupestre à história da arte, o que não deixa de ser uma aplicação da ideologia do progresso histórico dentro da estética, o que se aponta, na citação acima, é a ocorrência de um impulso fundamental na arte rupestre justamente lá onde prevalece a ausência da lógica esclarecedora: o de crítica à quantificação e à identidade. Assim, de maneira análoga à magia, que ainda continha uma relação mimética para com a coisa tida como objeto de feitiçaria, a arte rupestre pretendia apreender da realidade aquilo que foge das teias de determinação do sujeito - diferentemente das narrativas míticas, nas quais o sujeito se sobrepõe ao objeto. Os autores dos desenhos da caverna aceitavam a indeterminação da realidade e tal aceitação estava diretamente vinculada à forma naturalista de representar o mundo. Como se eles já intuíssem a possibilidade de, no futuro, a dominação da natureza fosse se tornar universal. Talvez um dos melhores exemplos disto seja a gravura "Pintura de Coletor-Caçador", que usa o recurso a uma ilusão espacial para promover um efeito estético: 


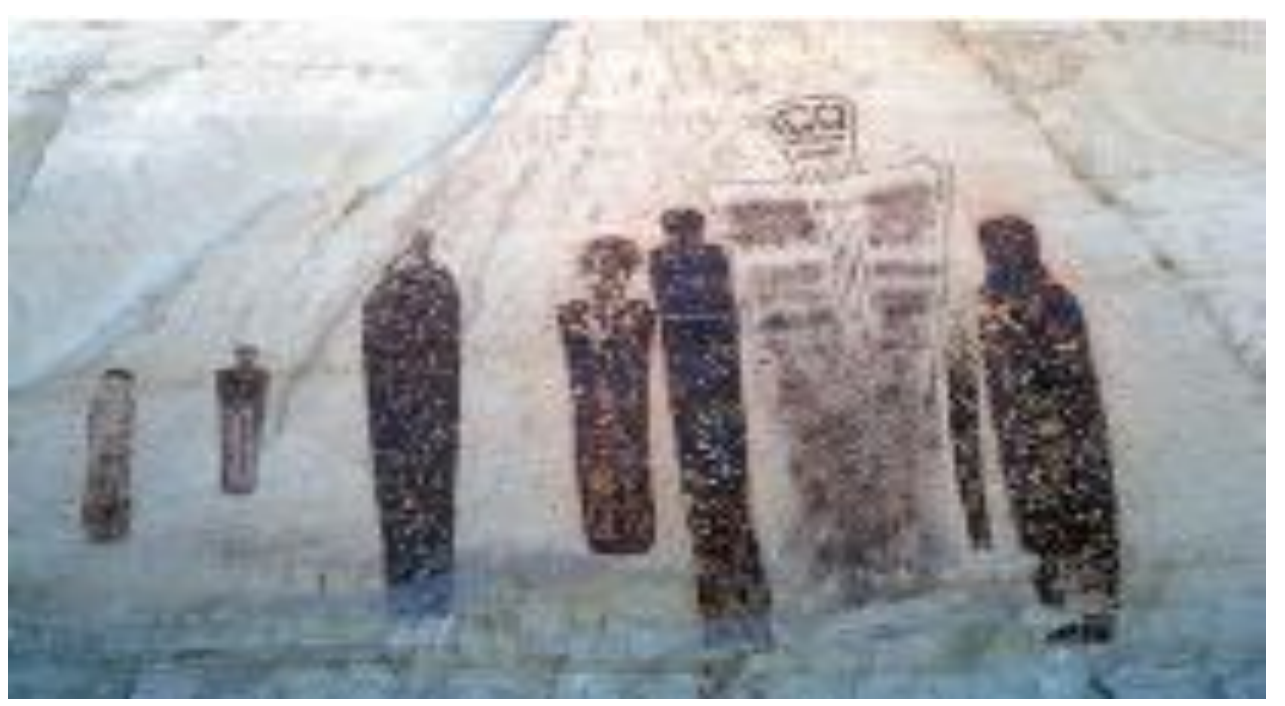

Figura 3: Pintura de Coletor-Caçador. Utah Oriental ( 5000a.C - 500 a.C) $(\text { SCHAAFSMA, 2013, p.5) })^{17}$.

Por outro lado, a possibilidade da reificação já ter começado na préhistória pode parecer à primeira vista absurda. Dizer que a "forma mercadoria" já era um fenômeno de dominação social objetivo muitos anos antes do advento das narrativas míticas - que deram início ao processo chamado por Adorno e Horkheimer de "Esclarecimento" - pode soar arbitrário, para não dizer estranho. Mas se levarmos em consideração o caráter cíclico da própria história natural, que até hoje reproduz a violência e a selvageria da natureza no âmbito social e cultural e que, sem dúvida, não se resume à categoria marxista de reificação, então tal tese tem um potencial de verdade que precisa ser levado em conta. Se, como nos diz Adorno, os primeiros desenhos das cavernas são protestos contra o processo da reificação, cada vez mais consumado em nossa era de saturação reificadora de reprodutibilidade técnica e de unidimensionalização da consciência coletiva, então a arte rupestre já possui em seu interior uma espécie de proto-história da reprodução técnica, bem como uma cripto-expressão, que seria então a representação da vontade da consciência primitiva de pôr termo ao sofrimento e a dor, libertando a natureza interna e externa do homem de seu destino mítico, que como tal mostrou-se trágico ao longo da marcha civilizatória.

\footnotetext{
${ }^{17}$ Comentando essa pintura, Schaafsma chama atenção para o fato de que nela ocorre uma ilusão de espaço tridimensional graças ao uso de figuras etéreas de diferentes tamanhos.
}

A estética dos extremos: notas sobre a relação entre a arte rupestre e a reprodutibilidade técnica em Theodor Adorno - Jéverton Soares dos Santos; Robson da Rosa Almeida 


\section{Referências bibliográficas}

ADORNO, Theodor. Ästhetische Theorie. Frankfurt am Main: Suhrkamp, 1990.

Minima moralia: reflexões a partir da vida danificada. $2^{\circ}$ Ed. São Paulo: Editora Ática, 1993.

Teoria Estética. Trad. Artur Morão. Lisboa: 70, 2013.

Dialética Negativa. Rio de Janeiro: Zahar, 2009.

Escritos filosóficos tempranos. Ediciones Akal: Madrid, 2010.

Filosofia da nova música. São Paulo: Perspectiva, 2011.

- Prismas. Trad. Augustin Wernet e Jorge Mattos Brito de Almeida. São Paulo: Editora Ática, 2001.

ADORNO, Theodor; BENJAMIN, Walter. Correspondência 1928-1940. Trad. José Marcos Mariani de Macedo. São Paulo: Editora Unesp, 2012.

ADORNO, Theodor; HORKHEIMER, Max. Dialectic of Enlightenment: Philosophical Fragments. Stanford University Press: California, 2012.

Dialéctica de la Ilustración: Fragmentos filosóficos. Editorial Trotta: Madrid, 1998.

Dialética do esclarecimento: fragmentos filosóficos. Rio de Janeiro: Jorge Zahar Editor, 1985. Reimpressão de 2006.

BENJAMIN, Walter. A obra de arte na era de sua reprodutibilidade técnica. In:

Magia, técnica, arte e política. São Paulo: Brasiliense, 2012.

O anjo da história. Belo Horizonte: Autêntica Editora, 2012.

BUCK-MORSS, Susan. Origen de la dialéctica negativa: Theodor W. Adorno, Walter Benjamin y el instituto de pesquisa de Frankfurt. Madri: Siglo Veintiuno Editora, 1981.

CROCE, Benedetto. The essence of aesthetic. Charleston, Nabu Press, 2010.

DUARTE, Rodrigo. Notas sobre modernidade e sujeito na Dialética do Esclarecimento. In: DUARTE, Rodrigo. Adornos: nove ensaios sobre o filósofo frankfurtiano. Belo Horizonte: Editora UFMG, 1997, pp. 45-63.

HABERMAS, Jürgen. O Discurso filosófico da modernidade. São Paulo: Martins Fontes, 2000.

JAMESON, Fredric. Marxismo tardio: Adorno ou a persistência da dialética. Trad. Luiz Paulo Rouanet. São Paulo: Editora Unesp, 1997.

RAMOS, Luciano. História do Brasil. São Paulo: Ed. do Brasil, 1977.

SCHAAFSMA, Polly. Images and Power: Rock Art and Ethics. New York: Springer, 2013.

TERZI, Marinella. Prehistoric Rock Art. Chicago: Child Press, [S.I].

WIGGERSHAUS, Rolf. A Escola de Frankfurt. História, desenvolvimento teórico, significação política. Rio de Janeiro: DIFEL, 2002.

WILDGEN, Wolfgang (2004). The Paleolithic Origins of Art, its Dynamic and Topological Aspects, and the Transition to Writing. In : Bax, Marcel,

A estética dos extremos: notas sobre a relação entre a arte rupestre e a reprodutibilidade técnica em Theodor Adorno - Jéverton Soares dos Santos; Robson da Rosa Almeida 
Barend van Heusden et Wolfgang Wildgen (éds.), 2004. Semiotic Evolution and the Dynamics of Culture, series: European Semiotics / Sémiotique Européenne, vol. 5. Bern : Lang : 117-153.

\section{Contribuição dos autores:}

Ambos os autores, Jéverton Soares dos Santos e Robson da Rosa Almeida participaram da discussão, revisão e redação do artigo. A versão final do texto foi aprovado pelos autores. 